\title{
Delftia acidovorans
}

National Cancer Institute

\section{Source}

National Cancer Institute. Delftia acidovorans. NCI Thesaurus. Code C86333.

A species of aerobic, Gram negative, rod shaped bacterium assigned to the phylum Proteobacteria. This species is motile by polar or bi-polar tufts of flag ella, does not hydrolyze esculin, indole negative and oxidase and catalase positive. D. acidovorans is found in soil and water and has been shown to be pathogenic in immunocompromised individuals. 